\title{
Optimasi Pola Pengasuhan Digital dalam Pemenuhan Kebutuhan Informasi
}

\author{
Mutia Rahmi Pratiwi1 ${ }^{1}$ Heni Indrayani2 ${ }^{2}$ Swita Amalia ${ }^{3}$ \\ 123 Universitas Dian Nuswantoro \\ Email: mutia.rahmi@dsn.dinus.ac.id, heni.indrayani@dsn.dinus.ac.id, \\ swita.amallia.hapsari@dsn.dinus.ac.id
}

Pratiwi, M. R., Indrayani, H., \&amp; Amalia, S. (2020). Optimasi Pola Pengasuhan Digital dalam Pemenuhan Kebutuhan Informasi. Expose: Jurnal Ilmu Komunikasi, 3(1), 76-94.
Received: 10-04-2020

Revision: 05-08-2020

Acceptance: $26-07-2020$

Published online: 30-08-2020

DOI: $10.33021 /$ exp.v3i1.1012

\section{English Title: Digital Parenting Optimization in Fulfillment Information Need}

\begin{abstract}
The implementation of parenting uses digital content to become the major source to gather information, in particular, parents these days. Digital parenting appears not only to provide the information that parents need but also to acknowledge about parenting through digital media. Moreover, the information is enlightenment and experienced by other parents so that it helps to use digital media. This paper examines the effect of digital parenting optimization and the fulfilment information need by the parents. This explanatory quantitative study was conducted with 100 parents that joined the parenting community and practiced the parenting pattern with a digital media platform to access the information. Furthermore, this study applied the purposive sampling technique. Data analyzing technique is to test the hypothesis with the simple linear regression model. The result of this study shows that the relation between digital parenting and fulfilment information need by the parents is significantly correlated. Also, the value of the correlation coefficient in the medium range is $R=04,16$ influence to the low range (0.173). Eventually, to fulfil the information for the parent need is not only gain by digital access.
\end{abstract}

Keywords: acces of information, digital parenting, parenting pattern

Abstrak Penerapan pengasuhan berbasis konten digital sebagai sumber informasi menjadi tantangan baru bagi orang tua masa kini. Pola pengasuhan digital (digital parenting) muncul karena akses informasi yang dilakukan oleh orangtua dalam memperoleh ilmu pengasuhan (parenting) melalui media digital. Akses informasi merupakan kualitas informasi yang diperoleh dan pengalaman subjektif yang dirasakan dalam menggunakan media digital. Penelitian ini bertujuan untuk menguji dan menganalisis mengenai pengaruh optimasi digital parenting dan pemenuhan kebutuhan informasi oleh orang tua. Metode penelitian yang digunakan adalah kuantitatif eksplanatif. Sampel penelitian sebanyak 100 orang tua yang tergabung dalam komunitas parenting dan melakukan pola pengasuhan dengan bantuan informasi di media digital. Teknik pengambilan sampel dilakukan dengan purposive sampling. Teknis analisis data untuk menguji hipotesis adalah dengan menggunakan regresi linier sederhana. Hasil penelitian menunjukkan bahwa ada hubungan yang signifikan antara digital parenting terhadap kebutuhan informasi, dengan nilai koefisien korelasi pada taraf sedang yaitu, $\mathrm{R}=0,416$ dengan pengaruh yang lemah (0.173). Hal ini menandakan bahwa pemenuhan informasi tidak hanya dari perilaku digital parenting saja. Orang tua mengasuh anaknya dengan mendapatkan informasi tidak hanya dari pemenuhan informasi secara online. 


\section{Kata Kunci: Digital Parenting; Pola Pengasuhan; Akses Informasi PENDAHULUAN}

Perkembangan media baru turut memberi ruang bagi keluarga masa kini dalam berkomunikasi secara efektif di lingkup keluarga melalui berbagai informasi yang tersaji. Informasi mengenai pola pengasuhan anak menjadi hal yang semakin mudah diakses. Hal ini dapat dilihat dari semakin banyaknya komunitas parenting yang menyajikan informasi, melalui berbagai media sosial yang ada. Berdasarkan hasil survei yang dilakukan oleh Asosiasi Pengguna Jasa Internet Indonesia (APJII) pada tahun 2019, pengguna internet di Indonesia sudah mencapai angka 171 juta jiwa, dilansir dari Katadata.co.id (Jayani, 2019). Berdasarkan survei yang dilakukan oleh Hootsuite pada Januari 2019 lalu, tercatat 56\% dari jumlah populasi yang ada di Indonesia terpenetrasi menggunakan internet.

Media baru menghadirkan keterlibatan interaksi orang tua dan anak, terutama saat menerapkan konten digital pengasuhan, yang diakses kemudian dicoba untuk diimplementasikan. Perkembangan teknologi dan zaman turut berperan pada tingginya kesadaran akan terbentuknya peer group hingga komunitas yang fokus pada segmentasi tertentu, beserta persoalan kompleks di dalamnya, termasuk komunitas parenting. Berdasarkan data yang diperoleh dari iprice.co.id, terdapat sepuluh situs web parenting yang memiliki insight terbaik, yaitu The Urban Mama, Mother\&Baby, Parenting, Ibu\&Anak, Katalog, Family Guide Indonesia, Rumah Inspirasi, dan The Asian Parent Indonesia. Pertumbuhan media sharing yang berperan sebagai digital parenting bertumbuh pesat dengan segmentasi yang berbeda sehingga terlihat dari tampilan dan konten yang diunggah.

Parenting atau pengasuhan merupakan bentuk merawat, membimbing, mengasuh, melatih dan memberi pengaruh dari orang tua ke anaknya (Afrilia, 2017). Menurut Baumrind, digital parenting didefinisikan seperti pola asuh yang berhubungan dengan gaya pengasuhan yang melibatkan internet. Para orang tua mencukupi kebutuhan waktu anak-anaknya untuk terkoneksi dengan digital dan beberapa aturan menggunakan teknologi dalam kegiatan sehari-hari (Oden, 2019). Orang tua memberi pengasuhan pada anak sejak lahir hingga dewasa, baik secara mental maupun psikologis. Hal ini juga diperkuat oleh Martinez \& Garcia (2017) bahwa orang tua membuat kendali, pengawasan, dan tuntutan kedewasaan dalam pengasuhan mereka; sedangkan responsif mengacu pada sejauh mana orang tua menunjukkan anak-anak mereka akan kehangatan dan penerimaan penuh kasih sayang, memberi mereka dukungan, dan bernalar dengan anak (Martínez, Murgui, Garcia, \& Garcia, 2019). 
Di era teknologi informasi, komunikasi menjadi dasar untuk menangkap realitas, mempersuasi hingga bagaimana kita berperilaku (Indrayani et al., 2019). Oleh karena itu, komunikasi dilakukan orang tua dalam mengasuh anak dan memanfaatkan media digital untuk dapat berkomunikasi dengan orang tua lainnya. Interaksi sosial dengan media digital dapat mengakibatkan ikatan yang kuat (misalnya, keluarga, teman) dalam memuaskan kebutuhan orang akan keterhubungan sosial (Mehl, Vazire, Holleran, \& Clark, 2010; Reis, Sheldon, Gable, Roscoe, \& Ryan, 2000; Vittengl \& Holt, 1998; Wheeler , Reis, \& Nezlek, 1983, Kushlev, Proulx, \& Dunn, 2017).

Misalnya saja, orang tua menggunakan blog untuk keperluan seperti ekspresi diri, keterlibatan sosial, dukungan teman sebaya, dan pertukaran informasi (Jang \& Dworkin, 2014). Orang tua muda saling bertukar informasi secara online untuk dapat mengungkapkan kekhawatiran mereka, mencari komentar yang mendukung, atau belajar melalui pengalaman orang tua muda lainnya.

Akses informasi merupakan bagaimana kualitas informasi yang diperoleh dan pengalaman subjektif yang dirasakan oleh masing-masing pengguna media digital (Tredinnick, 2006). Terdapat beberapa penelitian yang telah dilakukan peneliti lainnya terkait akses informasi. Penelitian yang dilakukan Barnes, Mbaru, \& Muthiga (2019) mengenai information access and knowledge exchange in co manage coral reef fisheries. Hasil penelitian menunjukkan bahwa pengelolaan yang dilakukan secara bersama-sama, dapat meminimalisir hambatan sosial dan budaya tradisional terhadap akses informasi, dan faktor sosial, budaya, dan ekonomi tetap penting untuk menyusun pertukaran pengetahuan antar anggota kelompok. Penelitian lainnya terkait akses informasi dilakukan oleh Aparacio, et al pada tahun 2018 menunjukkan bahwa adanya integrasi sumber informasi yang baik dengan penggunaan bahasa yang berbeda, dan penjelasan yang akurat sangat bermanfaat dalam keberlangsungan kegiatan pembelajaran (Aparicio et al., 2018).

Pola asuh menurut Diana Baumrind dibagi menjadi tiga tipe, yaitu: otoriter, demokratis, dan permisif. Otoriter atau authoritarian parenting terjadi ketika orang tua menerapkan aturan yang harus diikuti oleh anak. Demokratis atau authoritative parenting terjadi saat orang tua tetap memegang kendali pada anak namun mendorong anak untuk mandiri dan menghormati individualitas anak. Pola asuh permisif terjadi saat orang tua memberikan asuhan tanpa penerapan kedisiplinan pada anak (Santrock, 2002).

Terdapat penelitian sebelumnya yang membahas mengenai pola pengasuhan orang tua dikaitkan dengan penggunaan media sosial telah dilakukan oleh Rahmi, et al. pada tahun 2018 menunjukan bahwa para orang tua dalam melakukan pengawasan hanya mengimplementasikan empat dari tujuh ketrampilan literasi media. Pengawasan 
yang dilakukan oleh orang tua masih dalam tataran preventif tanpa mengkaji lebih dalam tentang isi media. Selain itu, orang tua memposisikan diri sebagai pengawas dengan melakukan beberapa hal berikut: penerapan aturan penggunaan media sosial yang ketat, melakukan pertemanan dengan anak di media sosial, pendekatan personal dan pemberlakuan pembatasan kuota (Pratiwi, Mukaromah, \& Herdiningsih, 2018).

Kebutuhan informasi muncul dari keadaan anomali pada pengetahuan. Para pencari informasi mencari apa yang tidak mereka miliki, sehingga adanya kebutuhan akan sesuatu yang dibutuhkan. Tindakan mencari informasi menunjukkan kurangnya pengetahuan tentang topik tertentu, misalnya: merasa kurang jelas terkait suatu hal atau topik tertentu. Kebutuhan informasi muncul dalam serangkaian tahapan, yaitu (Tredinnick, 2006):

1. Visceral need atau Kebutuhan yang mendalam. Mencakup perasaan, emosi, rasa ketidaknyamanan. Ketika kebutuhan ini tidak ditunjuk kan dalam kesadaran akan suatu kebutuhan informasi maka muncul keadaan "anomalous state of knowledge".

2. Conscious need atau kebutuhan yang disadari. Merupakan kebutuhan informasi mendasar yang pertama kali disampaikan atau diutarakan. Para pencari informasi menyadari adanya kebutuhan mendasar dan mulai memberikan batasan ruang masalah.

3. Formalised need atau membentuk kebutuhan. Merupakan kebutuhan informasi pada suatu hal yang disampaikan secara jelas dengan memberi batasan ruang lingkup dan membatasi ruang kebutuhan itu sendiri.

4. Compromised need atau kebutuhan yang dikompromikan. Merupakan kebutuhan informasi yang diterjemahkan melalui sistem informasi. Formalised need kemudian diterjemahkan menjadi suatu kebutuhan yang dikompromikan oleh adanya keterbatasan dari sistem informasi, seperti pencarian pernyataan yang disebut negosiasi dengan sistem informasi tertentu.

Menurut Baumrind, keberhasilan gaya pengasuhan berkaitan dengan beberapa latar belakang seperti kedekatan emosional, pendidikan, dan sensitivitas (Power, 2013). Maka digital parenting memiliki relevansi dengan aktivitas orang tua dalam mengoptimalkan penggunaan akses internet untuk memenuhi kebutuhan informasi. Gaya pengasuhan digital merujuk pada aktivitas orang tua yang memberikan waktu lebih banyak mengandalkan akses internet untuk mencari informasi. Selain itu, digital parenting juga menghabiskan waktu bermain internet bersama anak-anak memiliki batasan dan aturan penggunaan teknologi saat memanfaatkannya (Oden, 2019). 
Berdasarkan pada rujukan penelitian terdahulu pada proses pengasuhan anak, para orang tua mencoba untuk terus mencari informasi di platform digital. Persoalan pola pengasuhan yang beragam, dan penyebaran informasi di berbagai platform digital yang berdampak pada pemenuhan kebutuhan informasi orang tua, menjadi dasar dilakukannya penelitian ini. Oleh karena itu, Ho (Hipotesis nol) dalam penelitian ini adalah tidak adanya pengaruh antara digital parenting terhadap kebutuhan informasi. Sedangkan Ha (Hipotesis alternatif) menunjukkan adanya pengaruh antara digital parenting terhadap kebutuhan informasi. Penelitian bertujuan untuk mendeskripsikan digital parenting dan kebutuhan informasi, serta ingin mengetahui seberapa besar pengaruh antara optimasi digital parenting terhadap pemenuhan kebutuhan informasi oleh orang tua.

\section{METODOLOGI}

Metode penelitian ini adalah kuantitatif eksplanatif. Variabel dalam penelitian ini antara lain digital parenting sebagai variabel independen dan kebutuhan informasi sebagai variabel dependen. Penelitian kuantitatif merupakan penelitian yang dilakukan terkait dengan masalah di masyarakat yang didasarkan pada pengujian suatu teori yang tersusun atas variabel dan dianalisis dengan prosedur statistik (Trijono, 2015). Tujuan dari jenis penelitian kuantitatif adalah untuk menjelaskan atau menggambarkan suatu masalah yang hasilnya dapat digeneralisasikan. Pada penelitian ini, peneliti harus objektif dengan menguji terlebih dahulu apakah batasan konsep dan alat ukur sudah memenuhi prinsip reliabilitas dan validitas. Penelitian kuantitatif menguji teori atau hipotesis dimana hasilnya nanti akan mendukung atau menolak teori (Kriyantono, 2006).

Penelitian kuantitatif memiliki beberapa pendekatan, dan pada penelitian ini menggunakan pendekatan studi kuantitatif eksplanatif yaitu mengaitkan atau menggali sebab akibat antara dua variabel yang akan diteliti (Kriyantono, 2006). Sampel penelitian menggunakan total sampling, yaitu jumlah sampel yang sama dengan populasi. Populasi dalam penelitian sejumlah 100 orang tua yang tergabung dalam 10 komunitas parenting dan melakukan pola pengasuhan dengan bantuan berbagai informasi yang tersedia di media digital. Komunitasnya antara lain Komunitas orangtualogy, Keluarga Kita, Busui Berdaya Qita, Ibu peduli, Jurnalis perempuan, Kompakers Semarang, Parentalk.id, Ibupedia, Pos pelayanan terpadu, dan Talkparenting.

Teknik pengumpulan data menggunakan instrumen penelitian berupa kuesioner yang disebarluaskan melalui google form. Variabel Digital Parenting disusun berdasarkan Dishion and Mac Mahon (1998), di mana digital parenting dapat dilihat dari indikator pola asuh, aktivitas, dan pertemanan (Elsaesser, Russell, Ohannessian, \& Patton, 2017). Variabel kebutuhan informasi disusun berdasarkan pendapat Tredinnick (2006), bahwa kebutuhan informasi dilihat dari indikator kualitas informasi dan 
EXPOSE: Jurnal Ilmu Komunikasi

ISSN 2620-8105 | E-ISSN 2621-0304

Volume 03, No. 01, April, 2020

pengalaman subjektif. Instrumen diuji dengan uji validitas dan reliabilitas dan hasilnya valid untuk semua pertanyaan data kuesioner. Instrumen penelitian dapat dikatakan valid apabila $\mathrm{r}_{\text {hitung }}$ lebih besar dari $\mathrm{r}_{\text {tabel }}(\alpha ; \mathrm{n}-2)$. Kemudian teknik Alpha Cronbach digunakan untuk menguji reliabilitas instrumen, yang mana apabila koefisien reliabilitas $\left(r_{11}\right)>0,6$.

Teknis analisis data untuk menguji hipotesis adalah dengan menggunakan regresi linier sederhana. Sebelum melakukan uji regresi liner sederhana, dilakukan uji asumsi klasik antara uji normalitas, uji heteroskedastisitas, dan uji autokorelasi. Adapun rumus regresi liner sederhana adalah sebagai berikut :

$$
\mathrm{Y}=\mathrm{a}+\mathrm{bX}
$$

Keterangan

Y : Variabel Terikat

X : Variabel Bebas

a dan $b:$ Konstanta $=5 \%(0,05)$

\section{HASIL DAN PEMBAHASAN}

\section{Digital Parenting}

Digital parenting dapat dilihat melalui elemen seperangkat alat pengasuhan orang tua, aktivitas, dan pertemanan. Dalam elemen seperangkat alat pengasuhan orang tua, terdapat dua hal yang penting yaitu, perhatian dan pengawasan tingkah laku remaja.

Tabel 1.1. Elemen Alat Pengasuhan Orangtua: Perhatian

\begin{tabular}{|cc|c|c|c|c|}
\hline & & Frequency & Percent & Valid Percent & $\begin{array}{c}\text { Cumulative } \\
\text { Percent }\end{array}$ \\
\hline Valid & 1 & 1 & .9 & .9 & .9 \\
& 2 & 2 & 1.9 & 1.9 & 2.8 \\
& 3 & 12 & 11.2 & 11.2 & 14.0 \\
\cline { 2 - 6 } & 4 & 92 & 86.0 & 86.0 & 100.0 \\
\cline { 2 - 6 } & Total & 107 & 100.0 & 100.0 & \\
\hline
\end{tabular}

Perhatian menjadi salah satu elemen mengenai bagaimana orangtua memahami berbagai kebutuhan anak baik fisik maupun psikis. Dari seluruh responden yang terlibat 86\% menyatakan sangat setuju dan memperhatikan anak-anaknya sebagai salah satu cara pengasuhan yang dilakukan. Kurang dari $2 \%$ responden yang abai dan tidak 
melakukan cara pengasuhan dengan memperhatikan anaknya. Dengan memanfaatkan teknologi informasi, orang tua yang notabene usianya masih muda berinteraksi untuk menjawab permasalahan yang dihadapi dalam mengasuh anak. Orang tua mencari komentar dan saling belajar pengalaman dari informasi online sebagai bentuk perhatian dan cara asuh orang tua muda ini. Hal ini sejalan dengan pendapat Dishion \& McMahon (1998) yang menyatakan bahwa pola asuh didasari oleh perhatian yang diberikan orang tua kepada anaknya (Elsaesser, Russell, Ohannessian, \& Patton, 2017)

Tabel 1.2. Elemen Alat Pengasuhan Orangtua: Pengawasan

\begin{tabular}{|c|c|c|c|c|c|}
\hline & & Frequency & Percent & Valid Percent & $\begin{array}{c}\text { Cumulative } \\
\text { Percent }\end{array}$ \\
\hline \multirow[t]{5}{*}{ Valid } & 1 & 1 & .9 & .9 & .9 \\
\hline & 2 & 1 & .9 & .9 & 1.9 \\
\hline & 3 & 24 & 22.4 & 22.4 & 24.3 \\
\hline & 4 & 81 & 75.7 & 75.7 & 100.0 \\
\hline & Total & 107 & 100.0 & 100.0 & \\
\hline
\end{tabular}

Pengawasan tingkah laku remaja juga menjadi bagian dari elemen seperangkat alat pengasuhan orangtua untuk mengukur seberapa besar peran orang tua untuk mengontrol anak-anak terutama bagi anak remaja yang tengah mengalami pubertas dan cenderung melakukan penyimpangannya. Sebesar $75.7 \%$ responden menyatakan sangat setuju untuk melakukan pengawasan jika ada perilaku yang berbeda atau melihat perubahan sikap yang tidak seperti biasanya. Sementara kurang dari 1\% yang menyatakan tidak setuju jika melakukan pengawasan sebagai salah satu pola pengasuhan terhadap anaknya. Hal ini menandakan bahwa orang tua pada level authoritarian dan authoritative, dimana kontrol pengawasan orang tua tinggi (Elsaesser et al., 2017).

Salah satu pengawasan orang tua terhadap anak adalah dengan melihat aktivitas anak. Dari hasil yang diperoleh, sebesar $47 \% .7$ responden setuju jika mengetahui kegiatan yang dilakukan oleh anak. Termasuk jadwal dan keberadaan anak jika berada di luar rumah selalu diketahui oleh para orang tua. Sebanyak $13,3 \%$ orang tua yang menyatakan kurang setuju jika harus mengetahui keberadaan anak dan berbagai aktivitas yang dilakukan. 
EXPOSE: Jurnal Ilmu Komunikasi

ISSN 2620-8105 | E-ISSN 2621-0304

Volume 03, No. 01, April, 2020

Tabel 1.3. Pengawasan Orang Tua dengan Mengetahui Kegiatan Anak

\begin{tabular}{|rl|r|r|r|r|}
\hline & & & & \multicolumn{2}{c|}{$\begin{array}{c}\text { Cumulative } \\
\text { Percent }\end{array}$} \\
\hline Valid & Frequency & Percent & Valid Percent & .9 \\
& 1 & .9 & .9 & 13.1 \\
& 13 & 12.1 & 12.1 & 60.7 \\
\cline { 2 - 6 } & 51 & 47.7 & 47.7 & 100.0 \\
\hline & Total & 107 & 100.0 & 39.3 & \\
\hline
\end{tabular}

Untuk melihat dan mengukur pengawasan orang tua terhadap anak, pertemanan menjadi salah satu hal yang diperhatikan. Dua hal yang masuk dalam pertemanan adalah pendekatan orang tua dan pengungkapan diri anak.

Tabel 1.4. Pendekatan Orang Tua Terhadap Anak

\begin{tabular}{|c|c|c|c|c|c|}
\hline & & Frequency & Percent & Valid Percent & $\begin{array}{c}\text { Cumulative } \\
\text { Percent }\end{array}$ \\
\hline \multirow[t]{5}{*}{ Valid } & 1 & 2 & 1.9 & 1.9 & 1.9 \\
\hline & 2 & 5 & 4.7 & 4.7 & 6.5 \\
\hline & 3 & 32 & 29.9 & 29.9 & 36.4 \\
\hline & 4 & 68 & 63.6 & 63.6 & 100.0 \\
\hline & Total & 107 & 100.0 & 100.0 & \\
\hline
\end{tabular}

Pendekatan orang tua juga menjadi salah satu cara untuk melihat kegiatan pola pengasuhan orang tua dalam aktivitas yang dilakukan sehari-hari. Terlihat jika sejumlah $63,6 \%$ responden sangat setuju jika para orang tua perlu melakukan pendekatan terhadap anak-anaknya, agar anak semakin terbuka dengan aktivitas yang mereka lakukan dan membuat kedekatan terhadap orang tuanya. Sebanyak 4,7\% responden yang menyatakan kurang setuju jika perlu pendekatan khusus yang dilakukan oleh orang tua.

Pengungkapan diri menjadi terlihat karena sejumlah 63,6\% responden sangat setuju jika para orang tua perlu melakukan pendekatan terhadap anak-anaknya agar semakin terbuka dengan aktivitas yang mereka lakukan dan membuat kedekatan terhadap orang tuanya. Sebanyak 4,7\% responden yang menyatakan kurang setuju jika perlu pendekatan khusus yang dilakukan oleh orangtua. 
EXPOSE: Jurnal Ilmu Komunikasi

ISSN 2620-8105 | E-ISSN 2621-0304

Volume 03, No. 01, April, 2020

Tabel 1.5. Pendekatan Orang Tua terhadap Anak melalui Pengungkapan Diri

\begin{tabular}{|c|c|c|c|c|c|}
\hline & & Frequency & Percent & Valid Percent & $\begin{array}{c}\text { Cumulative } \\
\text { Percent }\end{array}$ \\
\hline \multirow[t]{5}{*}{ Valid } & 1 & 1 & .9 & .9 & .9 \\
\hline & 2 & 8 & 7.5 & 7.5 & 8.4 \\
\hline & 3 & 47 & 43.9 & 43.9 & 52.3 \\
\hline & 4 & 51 & 47.7 & 47.7 & 100.0 \\
\hline & Total & 107 & 100.0 & 100.0 & \\
\hline
\end{tabular}

\section{Kebutuhan Informasi}

Kebutuhan informasi dilihat dari kualitas informasi dan pengalaman subjektif. Kualitas informasi meliputi informasi yang membangkitkan, memprovokasi, menimbulkan amarah, informasi yang mendidik maupun informasi yang menghibur.

Berdasarkan hasil olah data, sebagian besar responden mencari informasi di internet untuk dapat membangkitkan semangat dalam mengasuh anak. Responden secara aktif mencari sumber informasi melalui platform digital. Tidak semua responden menyebarluaskan informasi yang didapat dari sumber internet ke lingkungan sosialnya, yaitu $31,76 \%$. Terdapat $42,99 \%$ setuju untuk memprovokasi lingkungannya bertindak sesuai dengan pengetahuan yang didapatkannya.

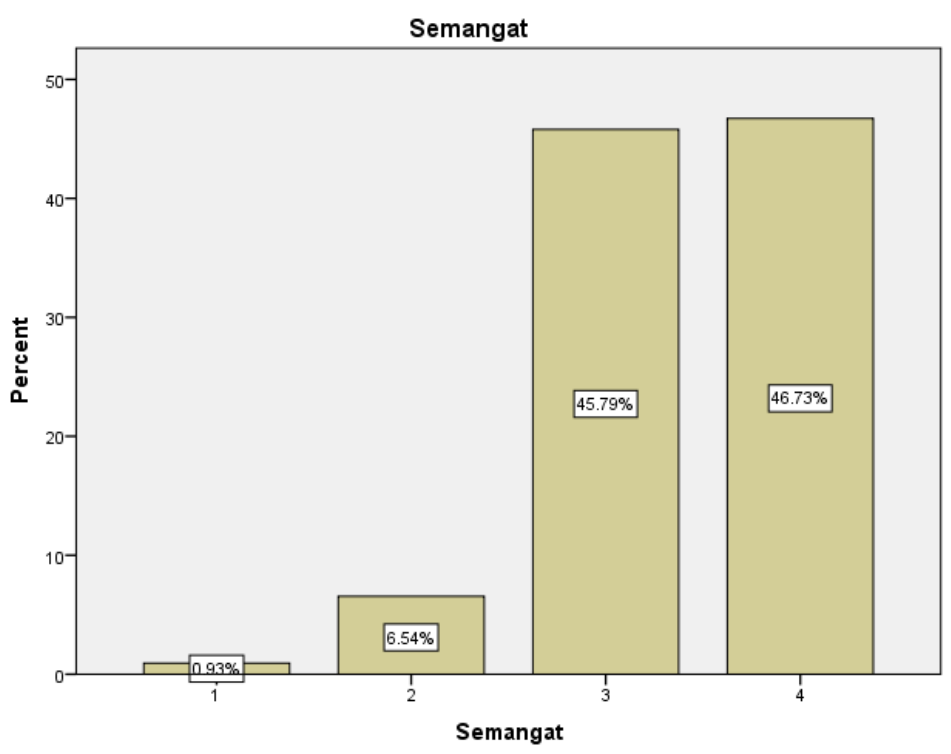

Gambar 1.1. Kualitas Informasi yang Memberi Semangat 
EXPOSE: Jurnal Ilmu Komunikasi

ISSN 2620-8105 | E-ISSN 2621-0304

Volume 03, No. 01, April, 2020

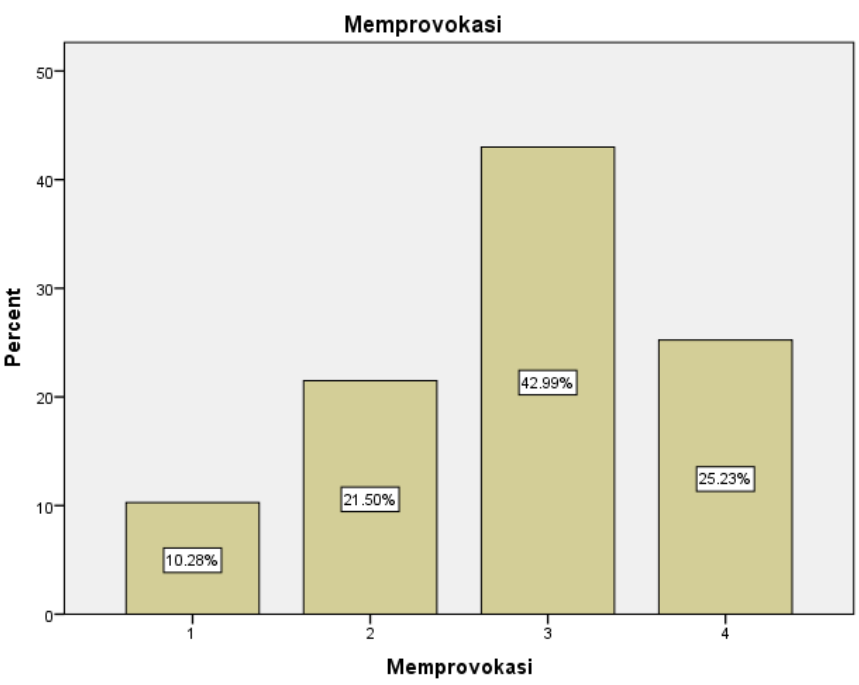

Gambar 1.2. Kualitas Informasi berupa Provokasi Terhadap Lingkungan

Sebagian besar responden mengaku bahwa mereka tidak setuju untuk memenuhi kebutuhan informasi dari internet untuk dapat melampiaskan kemarahannya. Namun, terdapat pula $12,15 \%$ yang sangat setuju untuk melampiaskan kemarahan di internet. Hal ini ditunjang dengan adanya ketidakjelasan identitas di internet sehingga mereka bisa melampiaskan kemarahannya.



Gambar 1.3. Tujuan Pencarian Informasi untuk Mendidik Anak

Sebagian besar responden sangat setuju untuk mencari informasi parenting untuk dapat mendidik anak dengan benar. Mereka menjadikan internet sebagai sumber informasi yang mudah diakses, sehingga $42,99 \%$ menyatakan sangat setuju jika mereka dapat mendidik anak dengan benar. Selain mendidik, responden seringkali mencari informasi parenting di internet hanya sekadar untuk hiburan. Sejumlah 36,45\% 
responden setuju jika menggunakan internet untuk "berselancar" mendapatkan informasi parenting karena dapat mengisi waktu luang yang dimilikinya.

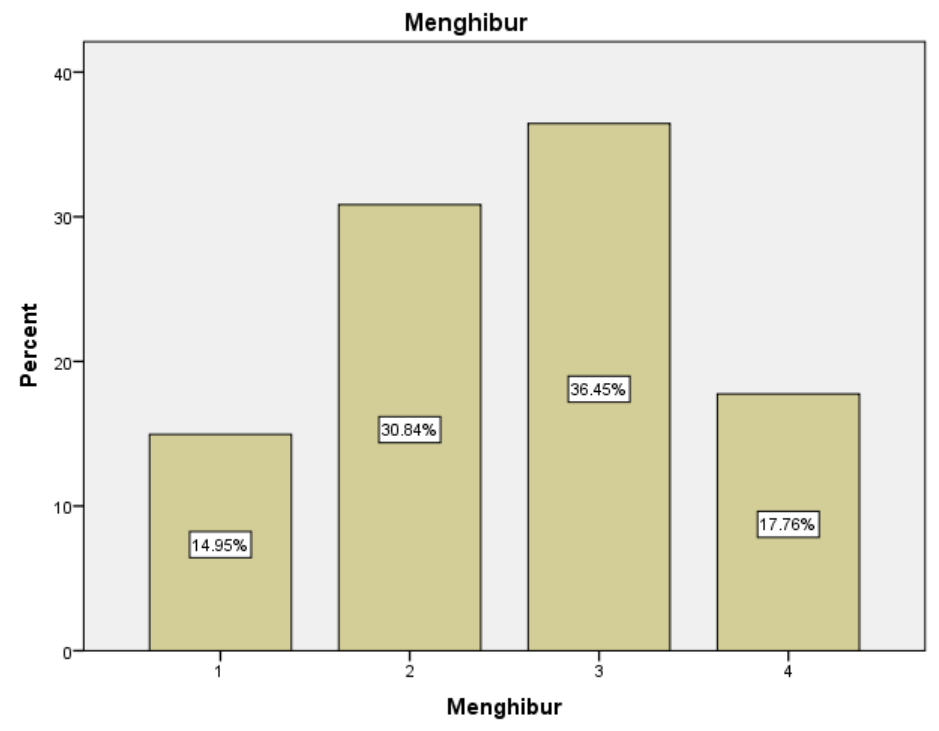

Gambar 1.4. Pencarian Informasi Sebagai Sarana Hiburan

Kualitas informasi dibagi menjadi empat yaitu, Visceral need, Conscious need, Formalised need, dan Compromised need (Tredinnick, 2006) Di antara semua indikator dalam kualitas informasi, membangkitkan semangatlah yang paling banyak menjadi kebutuhan informasi orang tua. Hal ini berarti membangkitkan semangat menjadi Visceral need (kebutuhan utama), di mana perasaan, emosi, rasa ketidaknyamanan menjadi bagian untuk mencari semangat dari informasi yang di media online. Upaya mendidik termasuk ke dalam Conscious need (kebutuhan yang disadari), di mana responden menyadari adanya kebutuhan mendasar untuk mencari tau cara mendidik anak yang benar. Sedangkan memprovokasi termasuk ke dalam formalised need, di mana ada batasan dalam kebutuhan informasi. Yang terakhir adalah, menimbulkan amarah dan upaya menghibur adalah menjadi bagian dari compromised need, di mana orang tua mencari informasi berdasarkan negosiasi kebutuhan.

Selain kualitas informasi yang menjadi indikator, pengalaman subjektif juga menjadi indikator lainnya. Pengalaman subjektif dapat dilihat dari sisi penerimaan, pengertian, dan perumusan kebutuhan informasi. Hampir $50 \%$ responden mendapat pengalaman dalam mengasuh anak dari informasi di internet. Namun terdapat pula $26,17 \%$ yang kurang setuju jika mereka mendapatkan cara mengasuh dari internet, dan $7,46 \%$ menyatakan tidak setuju. Hal ini berarti sebagian responden mendapat pengalaman dalam mengasuh dari sumber lain. 
EXPOSE: Jurnal Ilmu Komunikasi

ISSN 2620-8105 | E-ISSN 2621-0304

Volume 03, No. 01, April, 2020

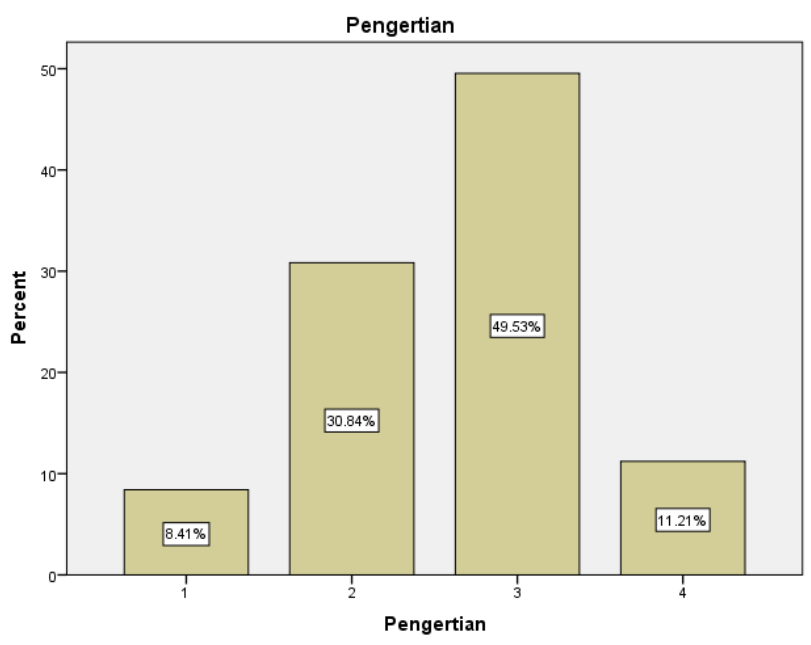

Gambar 1.5. Hasil Olah Data

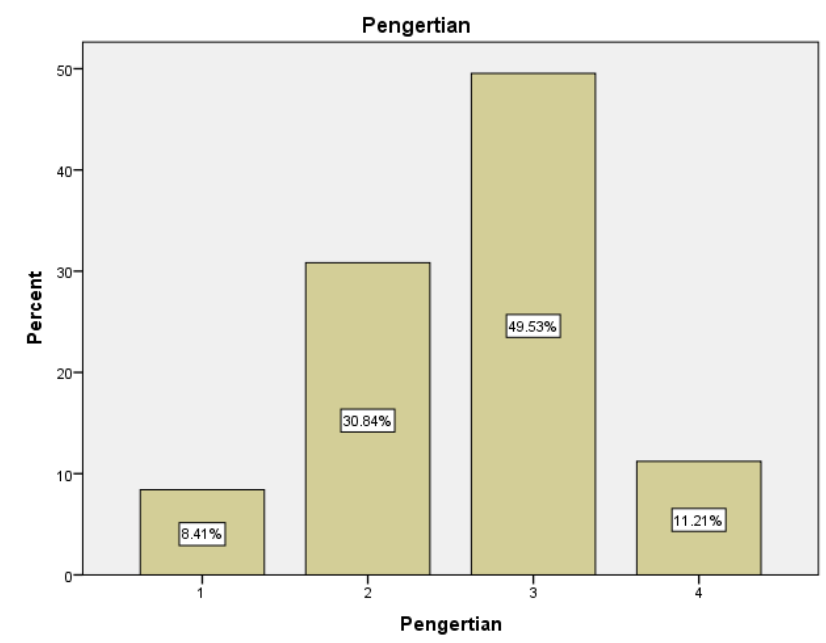

Gambar 1.6. Pengertian Orang tua Terhadap Karakter Anak

Sebanyak 49,53\% setuju bahwa mereka lebih bisa mengerti perkembangan anak dan memahami karakter anak dari informasi di internet. Namun, terdapat 30,84\% yang kurang setuju bahwa mereka mengerti perkembangan anak dan memahami karakter anak tidak hanya dari internet. 
EXPOSE: Jurnal Ilmu Komunikasi

ISSN 2620-8105 | E-ISSN 2621-0304

Volume 03, No. 01, April, 2020

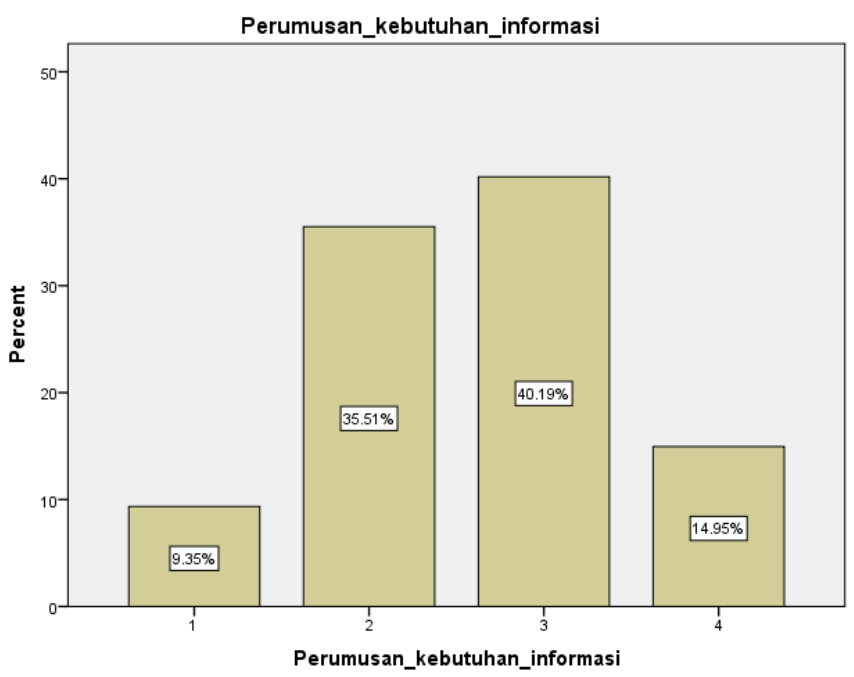

Gambar 1.7. Perumusan Kebutuhan Informasi Orang tua Melalui Media Digital

Tips dan trik di internet menjadi salah satu informasi yang disebarluaskan di internet. Sebanyak 40,19\% responden mengaku bahwa mereka mampu menyelesaikan permasalahan anak dari tips dan trik yang ada di internet. Namun juga terdapat 35,51\% yang kurang setuju bahwa tips dan trik menyelesaikan permasalahan anak dari sumber lain.

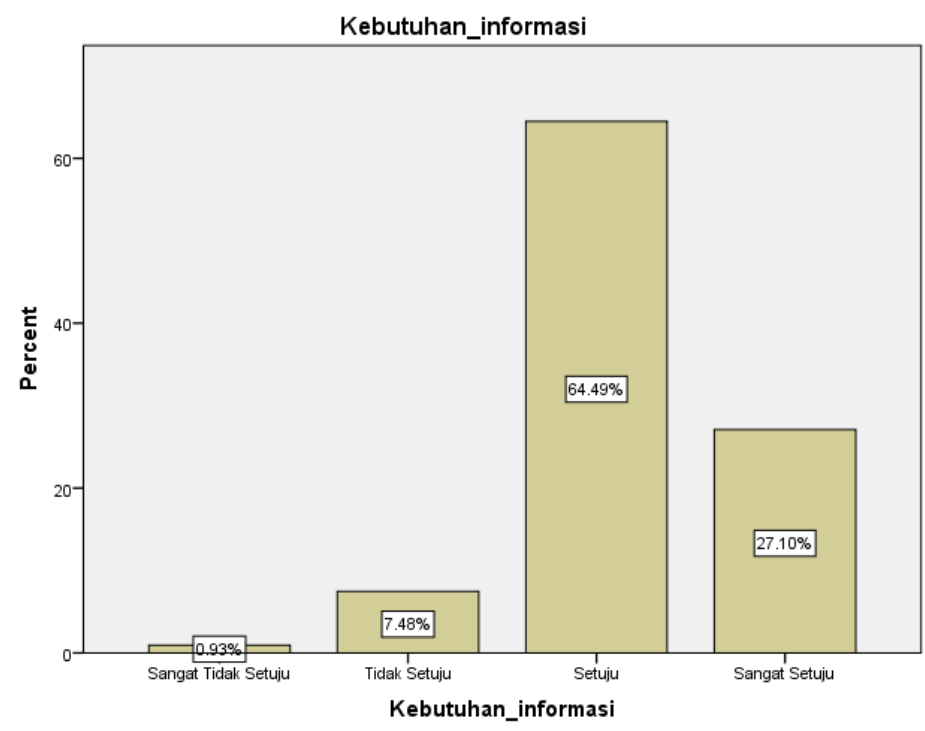

Gambar 1.8. Kebutuhan Informasi

Berdasarkan hasil penelitian, terkait penerimaan, pengertian, dan perumusan kebutuhan informasi, menunjukkan bahwa orang tua kebutuhan informasi dari tips dan trik menjadi pengalaman yang harus dimiliki mereka dalam membangkitkan semangat 
EXPOSE: Jurnal Ilmu Komunikasi

ISSN 2620-8105 | E-ISSN 2621-0304

Volume 03, No. 01, April, 2020

mengasuh. Subjektivitas dalam pesan berupa informasi online terkait dengan makna (Tredinnick, 2006). Maka penerimaan informasi tips dan trik menjadi makna yang berarti bagi orang tua dibanding dengan hal lainnya.

\section{Optimasi Digital Parenting dalam Pemenuhan Informasi}

Uji Normalitas

Ho adalah data berdistribusi normal, sedangkan Ha adalah data tidak berdistribusi normal. Berdasarkan pengujian distribusi normalitas data mengenai digital parenting dan kebutuhan informasi dengan Kolmogorov-Smirnov test, didapat hasil signifikansi 0,200 >0,025, maka Ho diterima yaitu, data berdistribusi normal.

Tabel 1.6. Uji Normalitas: One-Sample Kolmogorov-

Smirnov Test

\begin{tabular}{|ll|r|}
\hline & & $\begin{array}{r}\text { Unstandardi } \\
\text { zed Residual }\end{array}$ \\
\hline $\mathrm{N}$ & & 100 \\
Normal Parameters ${ }^{a, b}$ & Mean & .0000000 \\
& Std. & 1.05882047 \\
& Deviation & .386 \\
Most Extreme & Absolute & .314 \\
Differences & Positive & -.386 \\
& Negative & .386 \\
Test Statistic & & $.200 \mathrm{c}$ \\
Asymp. Sig. (2-tailed) & & \\
\hline
\end{tabular}

a. Test distribution is Normal.

b. Calculated from data.

c. Lilliefors Significance Correction.

Uji Heteroskedastisitas

Dalam uji heteroskedastisitas menunjukkan apakah nilai variabel bebas bersifat konstan. Hal ini memperlihatkan kondisi di mana sebaran data konstan. Berdasarkan tabel terlihat bahwa nilai siginifikansi sebesar 0,300, di mana nilai signifikansi $>0,05$ sehingga tidak terjadi heteroskedastisitas. 
EXPOSE: Jurnal Ilmu Komunikasi

ISSN 2620-8105 | E-ISSN 2621-0304

Volume 03, No. 01, April, 2020

Tabel 1.7. Uji Heteroskedastisitas: ANOVA ${ }^{a}$

\begin{tabular}{|c|c|c|c|c|c|c|}
\hline \multicolumn{2}{|c|}{ Model } & $\begin{array}{l}\text { Sum of } \\
\text { Squares }\end{array}$ & $\mathrm{df}$ & $\begin{array}{l}\text { Mean } \\
\text { Square }\end{array}$ & $\mathrm{F}$ & Sig. \\
\hline \multirow[t]{3}{*}{1} & Regression & .289 & 1 & .289 & 9.479 & $.300^{\mathrm{b}}$ \\
\hline & Residual & 2.991 & 98 & .031 & & \\
\hline & Total & 3.280 & 99 & & & \\
\hline
\end{tabular}

a. Dependent Variable: Abs_res

b. Predictors: (Constant), Parenting_monitoring

Uji Autokorelasi

Dalam pengujian autokorelasi menggunakan Durbin Watson. Hipotesisnya adalah H0 menunjukkan tidak adanya autokorelasi dan H1 menunjukkan adanya autokorelasi. Berdasarkan tabel uji autokorelasi menunjukkan bahwa nilai DW adalah 1,779, dU sebesar 1,6944, sehingga $\mathrm{dU}<\mathrm{DW}<(4-\mathrm{dU})$. Oleh karena itu, H0 diterima yang berarti tidak terjadi autokorelasi.

Tabel 1.8. Uji Autokorelasi: Model Summary ${ }^{b}$

\begin{tabular}{|l|r|r|r|r|r|}
\hline $\begin{array}{l}\text { Mode } \\
1\end{array}$ & $\mathrm{R}$ & R Square & $\begin{array}{c}\text { Adjusted R } \\
\text { Square }\end{array}$ & $\begin{array}{l}\text { Std. Error of } \\
\text { the Estimate }\end{array}$ & $\begin{array}{l}\text { Durbin- } \\
\text { Watson }\end{array}$ \\
\hline 1 & $.358^{\mathrm{a}}$ & .128 & .119 & .455 & 1.779 \\
\hline
\end{tabular}

a. Predictors: (Constant), Parenting_monitoring

b. Dependent Variable: Kebutuhan_informasi

Uji Regresi Linier Sederhana

Tabel 1.9. Model Summary

\begin{tabular}{|l|r|r|r|r|}
\hline Model & \multicolumn{1}{|c|}{$\mathrm{R}$} & $\mathrm{R}$ Square & Adjusted R Square & $\begin{array}{c}\text { Std. Error of the } \\
\text { Estimate }\end{array}$ \\
\hline 1 & $.416^{\mathrm{a}}$ & .173 & .165 & .544 \\
\hline
\end{tabular}

a. Predictors: (Constant), Parenting_monitoring 
EXPOSE: Jurnal Ilmu Komunikasi

ISSN 2620-8105 | E-ISSN 2621-0304

Volume 03, No. 01, April, 2020

Tabel 1.10. AnovaANOVAa

\begin{tabular}{|rr|r|r|r|r|r|}
\hline \multicolumn{1}{|c|}{ Model } & $\begin{array}{r}\text { Sum of } \\
\text { Squares }\end{array}$ & Df & $\begin{array}{l}\text { Mean } \\
\text { Square }\end{array}$ & F & Sig. \\
\hline 1 & Regression & 6.510 & 1 & 6.510 & 21.967 & $.000^{\mathrm{b}}$ \\
& Residual & 31.116 & 105 & .296 & & \\
Total & 37.626 & 106 & & & \\
\hline
\end{tabular}

a. Dependent Variable: Kebutuhan_informasi

b. Predictors: (Constant), Parenting_monitoring

Coefficients ${ }^{a}$

\begin{tabular}{|c|c|c|c|c|c|c|}
\hline & \multirow{2}{*}{ Model } & \multicolumn{2}{|c|}{$\begin{array}{l}\text { Unstandardize } \\
\text { d Coefficients }\end{array}$} & $\begin{array}{c}\text { Standardized } \\
\text { Coefficients } \\
\end{array}$ & \multirow{2}{*}{$\mathrm{t}$} & \multirow{2}{*}{ Sig. } \\
\hline & & B & $\begin{array}{l}\text { Std. } \\
\text { Error }\end{array}$ & Beta & & \\
\hline \multirow[t]{2}{*}{1} & (Constant) & 1.023 & .463 & & 2.212 & .029 \\
\hline & $\begin{array}{l}\text { Parenting_m } \\
\text { onitoring }\end{array}$ & .558 & .119 & .416 & 4.687 & .000 \\
\hline
\end{tabular}

a. Dependent Variable: Kebutuhan_informasi

Berdasarkan uji analisis data menggunakan regresi linear antara digital parenting dengan kebutuhan informasi menunjukkan bahwa, ada pengaruh yang signifikan antara digital parenting terhadap kebutuhan informasi dengan nilai koefisien korelasi pada taraf sedang yaitu $\mathrm{R}=0,416$. Oleh karena itu, hipotesis nol ditolak dan hipotesis alternatif diterima. Nilai koefisien determinasi (KD) adalah sebesar 17,3\%, yang ditafsirkan bahwa sebesar 17,3\% kebutuhan informasi dipengaruhi oleh digital parenting monitoring, sedangkan $82,7 \%$ dipengaruhi oleh variabel lainnya. Persamaan regresi adalah sebagai berikut :

$$
\mathrm{Y}=1,023+0,558 \mathrm{X}
$$

Dari persamaan regresi menunjukkan bahwa ada hubungan korelasi pada taraf cukup $(r=0.416)$ dengan pengaruh yang lemah. Hal ini sesuai dengan taraf korelasi menurut Siregar (2013: 337) bahwa nilai korelasi 0,40-0,599 termasuk pada taraf cukup. Hal ini menandakan bahwa pemenuhan informasi tidak hanya dari perilaku digital parenting saja. Orang tua mengasuh anaknya dengan mendapatkan informasi tidak hanya dari pemenuhan informasi secara online. Meskipun dengan adanya teknologi informasi memungkinkan berkoneksi dengan orang lain (Kushlev, Proulx, \& Dunn, 2017: 68), orang tua juga memenuhi kebutuhan informasinya dari faktor lain. 
Berdasarkan hasil olah regresi yang menunjukkan bahwa pengaruhnya berada pada taraf cukup, berarti bahwa optimasi digital parenting berpengaruh terhadap pemenuhan kebutuhan informasi. Digital parenting merupakan pola asuh yang berhubungan dengan gaya pengasuhan yang melibatkan internet, di mana orang tua mencukupi kebutuhan waktu anaknya untuk terkoneksi dengan digital dan beberapa aturan menggunakan teknologi dalam kegiatan sehari-hari (Oden, 2019). Optimasi digital parenting dilakukan orang tua melalui penggunaan media digital untuk keperluan seperti, ekspresi diri, keterlibatan sosial, dukungan teman sebaya, dan pertukaran informasi (Jang \& Dworkin, 2014).

Berdasar rujukan yang diperoleh, digital parenting dapat dilihat melalui alat pengasuhan orang tua, aktivitas, dan pertemanan. Pada penelitian ini diperoleh hasil yaitu orang tua memperhatikan anaknya sebagai salah satu cara pengasuhan yang dilakukan. Pengawasan yang dilakukan orang tua bertujuan mengetahui kegiatan yang dilakukan anaknya. Pertemanan diukur melalui pendekatan orang tua dan pengungkapan diri anak. Di mana lebih dari 50 persen orang tua melakukan pendekatan terhadap anaknya agar terjadi pengungkapan diri oleh anak.

Kebutuhan informasi muncul dari keadaan anomali pada pengetahuan sehingga pencari informasi mencari apa yang tidak mereka miliki dan muncul kebutuhan. Kebutuhan informasi dilihat dari kualitas informasi dan pengalaman subjektif. Orang tua yang melakukan pencarian informasi di internet bermanfaat untuk membangkitkan semangat dalam mengasuh anak sehingga proses pengasuhan dapat dilakukan dengan lebih baik dan benar. Para orang tua juga mendapatkan hiburan saat mereka menggunakan media digital sebagai dasar memenuhi pemenuhan kebutuhan informasi mereka. Setiap orang tua memiliki pengalaman subjektif yang berbeda saat mengakses informasi dari media digital. Beberapa orang tua menyatakan bahwa dalam pengasuhan anak mereka menggunakan informasi di media digital sebagai role model pengasuhan. Namun di sisi lain, responden lainnya tidak setuju akan hal ini. Sehingga dapat disimpulkan bahwa optimasi digital parenting yang dilakukan berpengaruh terhadap kebutuhan informasi yang dilakukan oleh orang tua.

\section{KESIMPULAN}

Hasil penelitian menunjukkan bahwa, berdasarkan uji analisis data regresi linear, antara digital parenting dengan kebutuhan informasi menunjukkan bahwa ada pengaruh pada taraf cukup antara digital parenting terhadap kebutuhan informasi dengan nilai koefisien korelasi pada taraf sedang yaitu $R=0,416$. Maka dapat disimpulkan bahwa hipotesis nol ditolak dan hipotesis alternatif diterima. Nilai koefisien determinasi (KD) adalah sebesar 17,3\%, yang ditafsirkan bahwa sebesar 17,3\% kebutuhan informasi dipengaruhi oleh digital parenting monitoring, sedangkan 82,7\% 
dipengaruhi oleh variabel lainnya. Berdasar persamaan regresi menunjukkan bahwa ada hubungan korelasi pada taraf cukup $(r=0.416)$ dengan pengaruh yang lemah.

Pada penelitian ini diperoleh hasil yaitu, orang tua memperhatikan anaknya sebagai salah satu cara pengasuhan yang dilakukan, dan orang tua melakukan pendekatan personal pada anak agar mengetahui aktivitas anak dan terjadi pengungkapan diri anak terhadap orang tuanya. Kemajuan teknologi dan ketersediaan media digital pada akhirnya memunculkan kebutuhan informasi pada orang tua yang dapat dilihat dari kualitas informasi dan pengalaman subjektif. Orang tua merasa bahwa pencarian informasi di internet bermanfaat untuk membangkitkan semangat dalam mengasuh anak dan sebagai media hiburan. Informasi di media digital menjadi media pemenuhan kebutuhan informasi, saat orang tua merasa kesulitan mengatasi persoalanpersoalan yang terjadi pada anak.

Penelitian mengenai digital parenting menjadi kajian yang sangat menarik untuk dilanjutkan bagi peneliti berikutnya dari berbagai sudut pandang, diantaranya: optimasi komunitas parenting, pola komunikasi interpersonal orang tua, maupun penggunaan media parenting sebagai media informasi orang tua milenial.

\section{DAFTAR PUSTAKA}

Afrilia, A. M. (2017). Penggunaan New Media di Kalangan Ibu Muda sebagai Media Parenting Masa Kini. Jurnal Komunikasi Dan Kajian Media, 1(1), 3142.

Aparicio, F., Morales-Botello, M. L., Rubio, M., Hernando, A., Muñoz, R., López-Fernández, H., ... Buenaga, M. de. (2018). Perceptions of the Use of Intelligent Information Access Systems in University Level Active Learning Activities Among Teachers of Biomedical Subjects. International Journal of Medical Informatics, 112(May 2017), 21-33. https:// doi.org/10.1016/j.ijmedinf.2017.12.016

Barnes, M. L., Mbaru, E., \& Muthiga, N. (2019). Information Access and Knowledge Exchange in Co-Managed Coral Reef Fisheries. Biological Conservation, 238(August), 108198. https:// doi.org/10.1016/j.biocon.2019.108198

Elsaesser, C., Russell, B., Ohannessian, C. M. C., \& Patton, D. (2017). Parenting in a digital age: A review of parents' role in preventing adolescent cyberbullying. Aggression and Violent Behavior, 35(August 2016), 62-72. https:/ / doi.org/10.1016/j.avb.2017.06.004

Indrayani, H., Hapsari, S. A., Cahyaningtyas, H. W., Hindami, R., Studi, P., Komunikasi, I., ... Pemasaran, K. (2019). Analisis Perkembangan Penelitian Komunikasi Pemasaran dan Konten Digital. 6(2), 118-134. 
Jang, J., \& Dworkin, J. (2014). Does social network site use matter for mothers? Implications for bonding and bridging capital. Computers in Human Behavior, 35, 489-495. https:/ / doi.org/10.1016/j.chb.2014.02.049

Jayani, D. H. (2019). Berapa Pengguna Internet di Indonesia? Retrieved January 4, 2020, from katadata.co.id website: https:// databoks.katadata.co.id/datapublish/2019/09/09/berapapengguna-internet-di-indonesia

Kriyantono, R. (2006). Teknik Praktik Riset Komunikasi. Jakarta: Kencana Jakarta.

Kushlev, K., Proulx, J. D. E., \& Dunn, E. W. (2017a). Digitally Connected, Socially Disconnected: The Effects of Relying on Technology Rather than Other People. Computers in Human Behavior, 76, 68-74. https:// doi.org/10.1016/j.chb.2017.07.001

Kushlev, K., Proulx, J. D. E., \& Dunn, E. W. (2017b). Digitally connected, socially disconnected: The effects of relying on technology rather than other people. Computers in Human Behavior, 76, 68-74. https:// doi.org/10.1016/j.chb.2017.07.001

Martínez, I., Murgui, S., Garcia, O. F., \& Garcia, F. (2019). Parenting in the digital era : Protective and risk parenting styles for traditional bullying and cyberbullying victimization. Computers in Human Behavior, 90(March 2018), 84-92. https:/ / doi.org/10.1016/j.chb.2018.08.036

Oden, M. S. (2019). Parenting Styles and Children's Usage of the Internet in the Digital Age. 109.

Power, T. G. (2013). Parenting dimensions and styles: A brief history and recommendations for future research. Childhood Obesity, 9(SUPPL.1), 1421. https://doi.org/10.1089/chi.2013.0034

Pratiwi, M. R., Mukaromah, \& Herdiningsih, W. (2018). Peran Pengawasan Orangtua pada Anak Pengguna Media Sosial. Jurnal Penelitian Pers Dan Komunikasi Pembangunan, 22(1), 37-57.

Siregar, S. (2013). Statistik Parametrik untuk Penelitian Kuantitatif. Jakarta: Bumi Aksara.

Tredinnick, L. (2006). Digital information, science and the social sciences. In Digital Information Contexts. https://doi.org/10.1016/b978-1-84334-1598.50003-2

Ventura, A. K., Levy, J., \& Sheeper, S. (2019). Maternal digital media use during infant feeding and the quality of feeding interactions. Appetite, 143(July), 104415. https:/ / doi.org/10.1016/j.appet.2019.104415 